\title{
Locating of Wind Power Farms by Analytic Hierarchy Process Method (Case Study: Sistan and Baluchistan Province, Iran)
}

\author{
Mehdi Asadi*, Mokhtar Karami \\ Department of Geography, Hakim Sabzevari University, Sabzevar, Iran \\ Email: ${ }^{\star}$ Asadimehdi11@yahoo.com
}

How to cite this paper: Asadi, M. and Karami, M. (2017) Locating of Wind Power Farms by Analytic Hierarchy Process Method (Case Study: Sistan and Baluchistan Province, Iran). Computational Water, Energy, and Environmental Engineering, 6, 4155.

http://dx.doi.org/10.4236/cweee.2017.61004

Received: September 27, 2016

Accepted: December 25, 2016

Published: December 28, 2016

Copyright (c) 2017 by authors and Scientific Research Publishing Inc. This work is licensed under the Creative Commons Attribution International License (CC BY 4.0).

http://creativecommons.org/licenses/by/4.0/

(c) (i) Open Access

\begin{abstract}
Limitation of fossil energy reserves in the world and increasing level of energy consumption, have always challenged human to replace new energy sources. Meanwhile, wind power as one of the new aspects of energy is of a special place. Due to the topography of the Sistan and Baluchistan province and its relative position, it is one of the best places to build wind farms. The aim of this study was to determine suitable locations for the construction of wind farms in the province. The following criteria were considered for various standards and due to the importance of data integration, Analytic Hierarchy Process (AHP) method was selected and implemented to weight the layer through Expert choice software. ArcGIS was used for layers spatial analysis and overlapping. After data analysis, the studied region, in terms of the susceptibility to build wind farms, was divided into four levels: excellent, good, fair, weak. Results indicated that GIS as a supportive and decision making system is helpful preparing data and modeling priorities and experts comments regarding various factors and help designers selecting a suitable place to build wind farms. In this study, we determined three priorities for the construction of wind farms, taking into account the limited overlap and conformity of limitations map and locating, the area of prioritized region, climate and the field observations; the priority order is excellent, good, average, including Zabol, central regions in Zabol and Chabahar.
\end{abstract}

\section{Keywords}

Wind Power, Energy, AHP, Sistan and Baluchistan

\section{Introduction}

The world is fast becoming a global village due to the increasing daily requirement of energy by all population across the world while the earth in its form cannot change. The need for energy and its related services to satisfy human social and economic de- 
velopment, welfare and health is increasing [1].

Utilizing wind energy has a long history and Iranian was the first whom used wind mills with vertical axis to flour grains and taking water from wells 200 B.C. Southern winds and particularly Sistan winds have traditionally been considered [2]. The extent of human demand on energy resources is always one of the critical issues. Trying to achieve an inexhaustible energy source has been always man's ancient dream. All fossil energy sources such as oil, gas, coal, and uranium, will end one day [3]. Human civilization, which depends on energy, will be disrupted with the exhaustion of non-renewable fossil energies. On the other hand, the consumption of fossil energy production sources has its own costs of material and environmental problems. The use of nuclear energy regardless of the environmental consequences such as nuclear waste, is expensive and requires advanced technology. This made human beings always seek new energy sources to replace these two sources of energy; the wind energy is affordable and available, and also its use does not create pollution. With regard to geographical, economic, environmental and geological parameters, one can find potential regions by application of GIS for wind farms. So far, several studies performed on the possibility of using wind energy potential in the different geographical areas including: Sharif Moghaddasi [4] studied wind energy in Iran. The study came to the conclusion that potential of wind energy is very high in Iran, and if this energy is used in correct way then can significantly impact the economy (reducing the cost of electricity...), and also reduces environmental pollution from emissions such as carbon dioxide generated.

Hamouda [5] has evaluated the economic feasibility of wind power in Cairo. In this study, half-hourly wind speed data used throughout the year 2009, and calculations indicated that although the wind energy resources in Cairo is poor, but wind power can be used to supply industry energy.

Masseran, et al. [6] evaluated wind power density obtained from several density function of wind speed in Malaysia. And based on the average density map of electric power in Malaysia several areas such as the North East, North West, the south area of the coast of Malaysia and the south of Sabah region determined as areas that show the best locations for wind energy development.

Baban and Parry [7] examined development and application of an approach using GIS to locate wind farms in the UK. They use two different methods to combine GIS data layers of Lancashire stations. First, all layers were considered equally important and given equal weight. Second, layers of information grouped and were ranked according to the degree of importance. They showed that these maps can be used to help the decision-making process and to find a suitable location for wind farms.

In other research, Bennui et al. [8] selected a suitable place for large wind turbines using GIS. The research was performed on five provinces of Thailand with the aim of applying a comprehensive GIS system by combining multiple criteria decision making (MCDM) to choose the more efficient location of wind turbines in the country. In this study, we used parameters of wind speed, altitude, slope, highways, railways, built areas, forest areas and scenic areas; finally, the best places to install wind turbines on the east coast of Thailand from Nakhon Si Thammarat province to Tom Mart Narathiwas have been selected. 
In this study, we attempted to identify the susceptible areas in the province using GIS and AHP method for the construction of wind farms and evaluated the area potential of electricity production.

\section{Material and Methods}

\subsection{The Study Area}

The study region, with an area of about 187,502 square kilometers, is one of the largest provinces of Iran, which is located between latitude of $25^{\circ} 3^{\prime \prime}$ and $31^{\circ} 27^{\prime \prime}$ north from and longitude of $58^{\circ} 50^{\prime \prime}$ to $63^{\circ} 21^{\prime \prime}$ east from the Greenwich meridian and this province has one of the lowest population density. This province consists of two regions of Sistan and Baluchestan and is bounded to South Khorasan and Afghanistan from north, to Pakistan and Afghanistan from east, to Oman Sea from South and to Kerman and Hormozgan provinces from west [9]. The location of study area is shown in Figure 1.

The location of wind farms as a question of making a decision needs materials and special tools. In this study, the data for period of 25 years from weather station in the province was used, and for spatial analysis and mapping criteria such as climatic, geographic, socio-economic, environmental and geological parameters ArcGIS 10.2.2 software was used. In order to study land use, we applied Landsat ETM + satellite related to 2014 and ENVI + 8 software was used for data analysis and interpretation. For weighting Information layers, Expert choice software was used. Figure 2 shows various stages of research.

\subsection{AHP Processing Method}

AHP is one of the best ways to decide when decision maker has multiple criteria [10] because they assist analysts or decide to organize the sensitive and vital issues [11]. Analytic hierarchy process begins identifying and prioritizing the elements of decision-making including objectives, criteria and potential options that may be used in prioritizing process. In the process, identifying elements and the relationship between

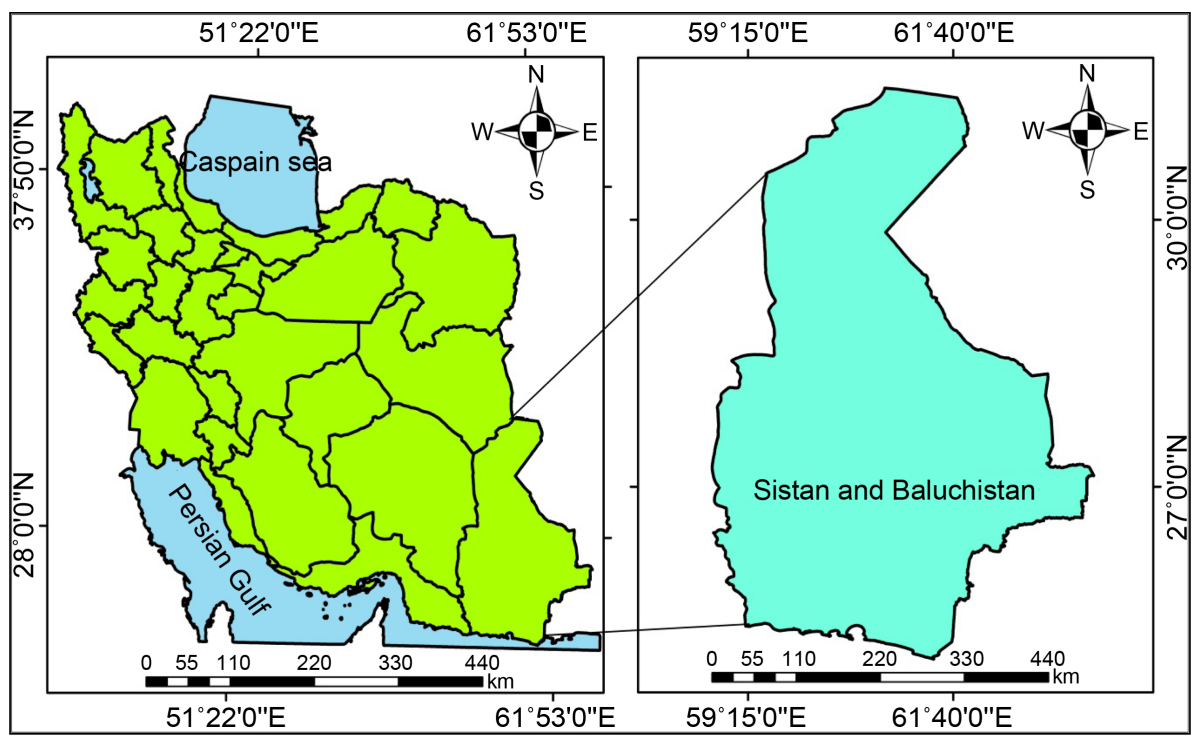

Figure 1. The location of study area in Iran. 


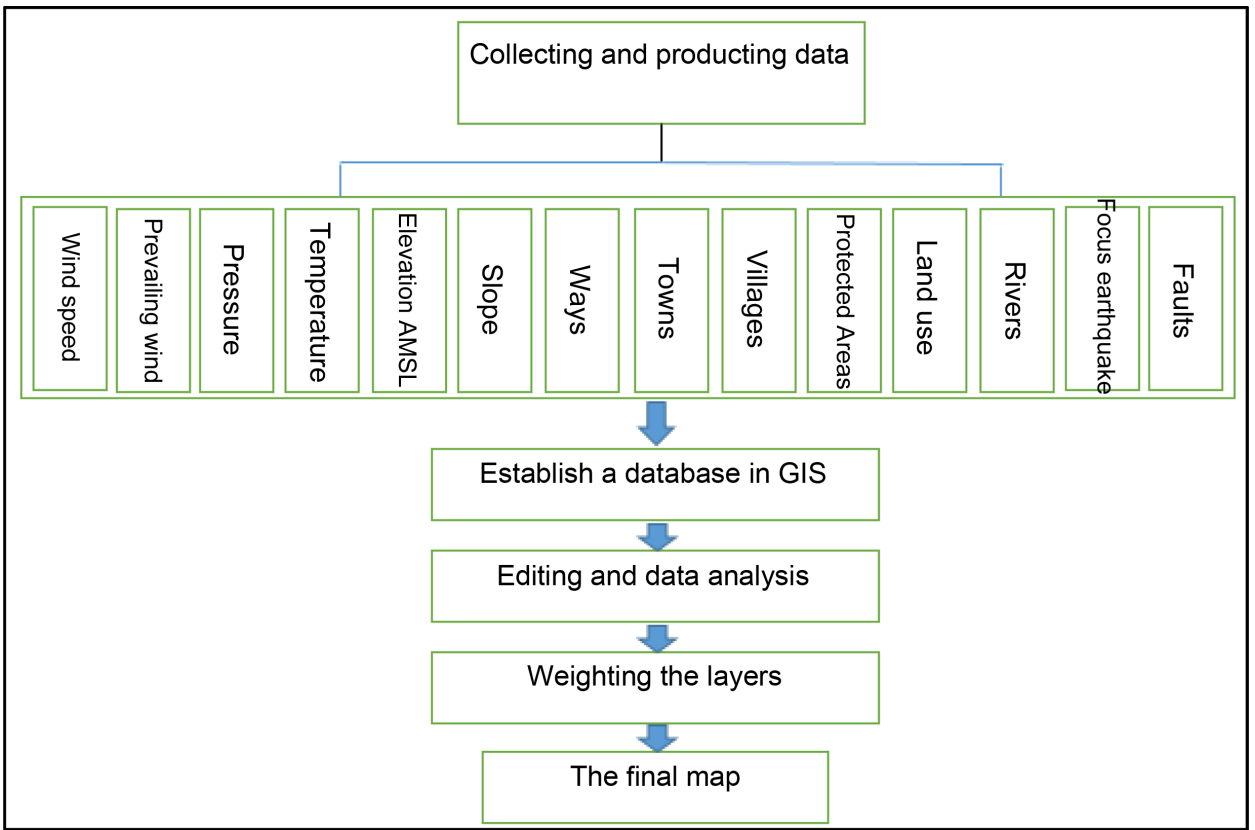

Figure 2. Various research steps.

them is to create a hierarchical structure. Because structure of summarizing of decision-making elements is such as the chain of at different levels it is hierarchal. So, to create a hierarchical structure of the object under study is the first step in the analytic hierarchy process and objectives, criteria and options, as well as their relationship are shown in the same structure. The next steps in the analytic hierarchy process, criteria and sub-criteria weight measurement (coefficient of significance) and calculate the options coefficient of importance (weight), the final calculation of options and check logical consistency of judgments [12] [13] [14].

In all processes, particularly the process of locating, evaluating is emphasized as one of the important parts of planning. Thus, after determining the overall aims and stated objectives and provide various options to achieve optimum location, the evaluation is conducted such that the desirable or better options to be selected based on adequacy [15].

Criteria are commonly used to assess the relative merits of each option. Select a suitable site for the construction of wind farms, or in other words the positioning this rule is no exception. AHP model starts identifying the decision-making process and elements and prioritize them, these elements include different ways of doing things and prioritize the features [16].

\subsection{Hierarchical Structure Creation}

AHP enables decision makers to provide a complex structure as a simple hierarchy. It also enables them to assess lots of qualitative and quantitative factors systematically in a multiple criteria situation [17]. Using the analytic hierarchy process to solve complex problems is usually performed in four stages [18].

1) Degrading complex problems to a number of minor elements and then forming a hierarchy for the elements. 
2) Pairs comparison of elements according to a ratio scale.

3) Using eigenvalues (matrix) to estimate the relative weight of the elements.

4) Using relative weights sum and combination of options for the final measurement. In other words, in any hierarchical structure relating to a specific subject, one faces with four hierarchical levels: objectives, criteria, sub-criteria, and options [19] [20].

\subsection{Determining the Importance of Criteria and Sub-Criteria}

Priority among the options is determined by a pair-wised comparison in AHP. The pair-wised comparison is done such that one of the options is selected and the priority of both is measured [21]. In this process the numbers 1 to 9 are applied as a standard scale to determine the importance of the options (from equal importance to extremely high importance). In a paired comparison matrix, 9 indicates extremely high importance of an option compared to other and 1.9 indicates that an option is extremely low important compared to other while 1 shows equal importance [22] [23]. So, if the importance of first factor to the second factor gained the importance of the second factor to the first factor will be reciprocal (Table 1). Also ratio scale and verbal comparison are applied to weight quantifiable non-quantifiable elements [24].

\subsection{Determining Final Score (Priority) of Options}

Coefficients of the criteria and the sub-criteria significance associated with the study as well as significance coefficients (scores) of options in relation to each of the sub-criteria are determined and specified already. At this point, we will determine the final score of each of the options integrating significance coefficients. To do so, we will use Saaty's "principle of hierarchical combination" that leads to the vector of priority, with respect to all judgments at all levels of the hierarchy [28]. The following equation shows how to calculate the final score of an option. Final score of options:

$$
=\sum_{k=1}^{n} \sum_{i=1}^{m} w_{k} w_{i}(g i j)
$$

where: $w_{k}$ is significance coefficient of criterion $k, w_{i}$ is significance coefficient of sub-criterion $i$, gij is the score of option $j$ related to sub-criterion I [28].

\subsection{Compliance Rates}

One of the advantages of hierarchical process is that it determines the rate of consistency of comparisons. This rate shows how much can be trusted to preferences or

Table 1. Points scale of 9 hourly for paired comparison [25] [26] [27].

\begin{tabular}{ccc}
\hline Score & Definition & Description \\
\hline 1 & Equally important & Two criteria are equally important in an objective research. \\
3 & Fairly high important & Experiments indicate that the $i$ importance is higher than $j$. \\
5 & Highly important & Experiments indicate that the i importance is very higher than $j$. \\
7 & Extremely high important & Experiments indicate that $i$ importance is extremely higher than $j$. \\
9 & Absolutely important & The very higher importance has been established. \\
$2,4,6,8$ & Average score between two & \\
\hline
\end{tabular}


priorities achieved by members of group or the priorities of combined tables. Experience has shown that if the consistency rate (CR) is less than 0.10 , consistency of comparisons can be accepted, otherwise comparisons must be repeated [29].

\section{Results and Discussion}

\subsection{Weighting of Criteria}

The first step is to determine the weighting of criteria. These weights are determined regarding the significance of measures against each other proportionate to the purpose of "locating the construction of wind farms". The main criteria are initially compared to each layer. Table 2 compares the test criteria of the original layer in the location of wind farms and Figure 3 shows the calculated weight standards through the Expert Choice software.

\subsection{Climate Criteria}

Climate criteria are among the most important parameters for construction of wind power plants. In this research, climate elements was more important than the other criteria and thus to have more weight. In this regard, climate parameters, wind speed, dominant wind speed, pressure and temperature are among climate sub-criteria that have been selected for the location of wind farms.

\subsection{Geographical Criteria}

Geographical criteria are major factors of locating and construction of wind farms. The geographic sub-criteria under study are altitude and slope of the ground which after weighting in the ArcGIS were studied and analyzed.

\subsection{Socio-Economic Criteria}

Other important criteria must be considered for the location of wind farms are socioeconomic ones. Socio-economic criteria include the criteria of distance communication

Table 2. Paired comparison of main criteria's for locating wind farm plants.

\begin{tabular}{ccccccc}
\hline Locating criteria & Climate & Geography & Socio-economies & Environment & Geology & Weight \\
\hline Climate & 1 & 3 & 6 & 6 & 6 & 0.515 \\
Geography & - & 1 & 3 & 3 & 3 & 0.221 \\
Socio-economies & - & - & 1 & 3 & 3 & 0.129 \\
Environment & - & - & - & 1 & 3 & 0.082 \\
Geology & - & - & - & - & 1 & 0.053 \\
\hline
\end{tabular}

\begin{tabular}{|c|c|}
\hline $\begin{array}{l}\text { Priorities with respe } \\
\text { Goal: site selection }\end{array}$ & ect to: \\
\hline CLIMATE & 0.515 \\
\hline GEOG RAPHICAL & 0.221 \\
\hline SOCAIL - ECONOMIC & 0.129 \\
\hline ENVIRONMENT & 0.082 \\
\hline GEOLOGY & 0.053 \\
\hline $\begin{array}{l}\text { Inconsistency }=0.08 \\
\text { with } 0 \text { missing jud }\end{array}$ & dgment \\
\hline
\end{tabular}

Figure 3. The calculated weights of geological criteria. 
(minor roads, major roads, and railways), distance from towns and villages (population centers).

\subsection{Environmental Criteria}

Now, noting environmental issues for locating wind farms is an important research purposes worldwide. Environmental criteria including the sub-criteria of distance from protected areas, land use and the distance from the river.

\subsection{Geological Criteria}

The following geological criteria used in this study: the distance from the epicenter of the earthquake (seismic) and distance to faults.

\subsection{Sub-Criteria Weights}

Given that for each criterion, sub-criteria have been defined, at this stage, for weighting the sub-criteria, they are mutually compared. Thus for each of them, paired comparison is done separately. In remaining sections, we will discuss them one by one.

\subsection{Climatic Sub-Criteria}

Wind speed, dominant wind speed, pressure and temperature are among the climate parameters which after weighting in Software Expert choice they are analyzed and evaluated in the software ArcGIS. Table 3 shows paired comparison of the climate criteria and Figure 4 shows the calculated weights.

\subsection{Geographical Sub-Criteria}

Geographical sub-criteria include altitude and slope. After being weighted in the Expert Choice software, these layers were analyzed in a GIS environment. Figure 5 shows calculated weights and Table 4 compares the geographical Sub-criteria in a paired form.

Table 3. Paired comparison of climate criteria.

\begin{tabular}{cccccc}
\hline Climate sub-criteria & Wind speed & Prevailing wind speed & Pressure & Temperature & Weight \\
\hline Wind speed & 1 & 3 & 5 & 5 & 0.549 \\
Prevailing wind speed & - & 1 & 3 & 3 & 0.248 \\
Pressure & - & - & 1 & 3 & 0.129 \\
Temperature & - & - & - & 1 & 0.074 \\
\hline
\end{tabular}

\begin{tabular}{|c|c|}
\hline Vind speed & 0.549 \\
\hline revailing wind speed & 0.248 \\
\hline essur & 0.129 \\
\hline emperature & 0.074 \\
\hline
\end{tabular}

Figure 4. The calculated weights of climate sub-criteria. 


\subsection{Socio-Economic Sub-Criteria}

Socio-economic sub-criteria include distance from roads, distance from the cities and the villages. After being weighted by ArcGIS software, these criteria were analyzed such that after producing restores of distance from each one the weights assigned to all various layers of sub-criteria. Table 5 compares socio-economic in a paired form and Figure 6 shows a comparison of the socio-economic sub-criteria.

\subsection{The Environmental Standards}

Distance from the protected areas, land use and the distance from the river have been considered as the environmental sub-criteria and after weighing entered into ArcGIS software and they were analyzed using the Spatial Analyst extension. This analysis includes the restores production for the sub-criteria and assigning calculated weights. Table 6 shows paired comparison of sub-criteria for environmental criteria. Figure 7 shows a comparison of the environmental sub-criteria.

\subsection{Weight of Options}

After determining the weight of sub-criteria, we determined the weight of options and evaluated the significance of each option versus the other. Here, because of the multiplicity of comparisons, we only indicated 2 of them (wind speed and fault) (Table 7 and

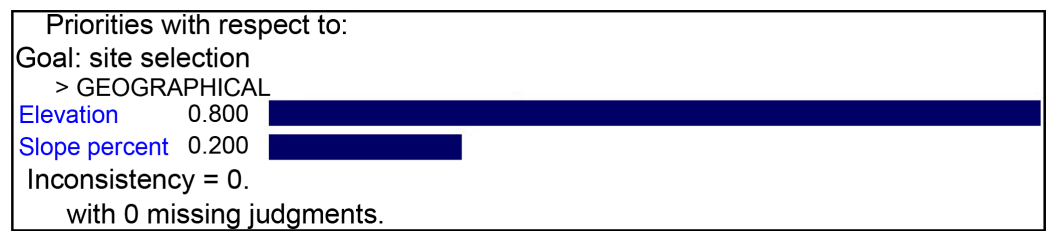

Figure 5. The calculated weights of geographical sub-criteria.

Priorities with respect to:
Goal: site selection
> SOCIAL - ECONOMIC
Roads $\quad 0.655$
Cities $\quad 0.250$
Villages $\quad 0.095$
Inconsistency $=0.02$
with 0 missing judgments.

Figure 6. Paired comparison of socio-economic sub-criteria.

Table 4. Paired comparison of geographical sub-criteria.

\begin{tabular}{cccc}
\hline Geographical sub-criteria & Altitude from sea level & Slope & Weight \\
\hline Altitude from sea level & 1 & 4 & 0.800 \\
Slope & - & 1 & 0.200 \\
\hline
\end{tabular}

Table 5. Paired comparison of the socio-economic sub-criteria.

\begin{tabular}{ccccc}
\hline Socio-economic sub-criteria & Distance from roads & Distance from towns & Distance from villages & Weight \\
\hline Distance from roads & 1 & 3 & 6 & 0.655 \\
Distance from towns & - & 1 & 3 & 0.250 \\
Distance from villages & - & - & 1 & 0.095 \\
\hline
\end{tabular}


Table 8) (Figure 8 and Figure 9).

\subsection{Determining the Final Score (Priority) of Options}

At this point, the final score was determined for each of the options combining the mentioned significance coefficient. To do so, Saaty's "principle of hierarchical combination" was used that leads to the priority vector with respect to all judgments at all

Table 6. Paired comparison of sub-criteria for environmental criteria.

\begin{tabular}{ccccc}
\hline Environmental sub-criteria & Distance from protected area & Land use & Distance from river & Weight \\
\hline Distance from protected area & 1 & 2 & 3 & 0.540 \\
Land use & - & 1 & 2 & 0.297 \\
Distance from river & - & - & 1 & 0.163 \\
\hline
\end{tabular}

Table 7. Paired comparison of wind speed options.

\begin{tabular}{cccccc}
\hline Wind speed options (knot) & $5-6$ & $6-8$ & $8-10$ & $10-12$ & Weight \\
\hline $5-6$ & 1 & 3 & 4 & 7 & 0.055 \\
$6-8$ & - & - & 1 & 6 & 0.105 \\
$8-10$ & - & - & 1 & 5 & 0.206 \\
$10-12$ & - & - & - & 1 & 0.634 \\
\hline
\end{tabular}

Table 8. Paired comparison of fault options.

\begin{tabular}{ccccccc}
\hline Distance from faults options $(\mathrm{km})$ & $0-1$ & $1-6$ & $6-10$ & $>10$ & Weight \\
\hline $0-1$ & 1 & 3 & 4 & 5 & 0.068 \\
$1-6$ & - & 1 & 3 & 5 & 0.125 \\
$6-10$ & - & - & 1 & 3 & 0.260 \\
$>10$ & - & - & - & 1 & 0.547 \\
\hline
\end{tabular}

\begin{tabular}{|l|}
\hline Priorities with respect to: \\
Goal: site selection \\
$\quad>$ ENVIRONMENT \\
Protected Area 0.540 \\
Land use $\quad 0.297$ \\
surface water $\quad 0.163$ \\
Inconsistency $=0.00877$ \\
$\quad$ with 0 missing judgments. \\
\hline
\end{tabular}

Figure 7. Calculated weights of sub-criteria for environmental criteria.

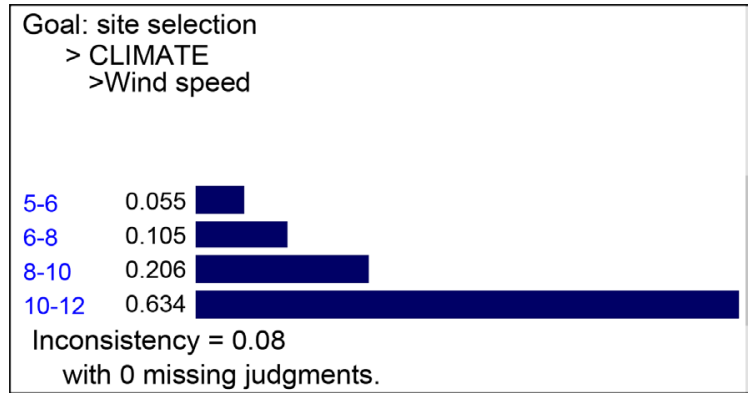

Figure 8. Calculated weights of wind in various speeds. 
levels of the hierarchy [6]. In simple terms by multiplying each of the criteria to the relevant sub-criteria and by multiplying obtained number to points corresponding score, the final score is obtained for each of the options.

\subsection{Integrating Information Layers}

After all information layers being provided and determining affective factors on locating wind farm plants and their roles over locating and through modeling and spatial analysis via GIS; we practiced to provide maps of those factors. After weighting the layers involved in locating wind farms based on the analytic hierarchy process (AHP), the capabilities of geographic information systems (GIS) were applied to integrate and overlap maps and locations map for wind plants was prepared. The resulting map was classified in four classes (excellent, good, fair and poor). An excellent area for the construction of wind farms in the north area of the study is located in Zabol station with an area of 72.0789842 hectares. Good areas with an area of over 95.186327 hectare in traces include southwest stations of Zabol, Zahedan, Saravan, Khash and Chabahar. However, the fair class with an area of over 79.9285437 hectare includes a wide range of South, Central and East area of the study covering approximately $0.53 \%$ of province area. Table 9 and Figure 10 show areas and locations suitable for construction of the wind farm, respectively.

\subsection{Minimum Restrictions Assigned on Layers}

Over operations and localization researches and in order to prevent waste of time and money, destruction of the environment and animal life as well as protect against natural disasters (earthquakes, floods...), minimum limits considered. This was performed on ArcGIS in a binary form or 0 and 1 . Areas located within determined distance were assigned 0 and those in a suitable position assigned 1. Figure 11 shows a map of areas bearing limitation. Table 10 and Table 11 show characteristics indicating areas with

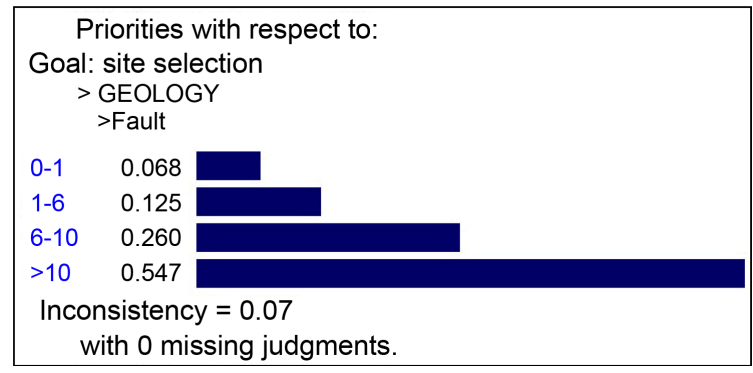

Figure 9. Calculated weights of distance from fault.

Table 9. Characteristics of location map.

\begin{tabular}{ccccc}
\hline Range & No. & Classification & Area (ha) & \% of province area \\
\hline \multirow{4}{*}{ Whole region } & 1 & poor & $5,799,038.17$ & 32.71 \\
& 2 & Fair & $9,285,437.79$ & 52.34 \\
& 3 & Good & $1,863,327.95$ & 10.50 \\
Total area & 4 & excellent & $789,842.72$ & 4.45 \\
& 5 & - & $17,737,881.42$ & 100 \\
\hline
\end{tabular}




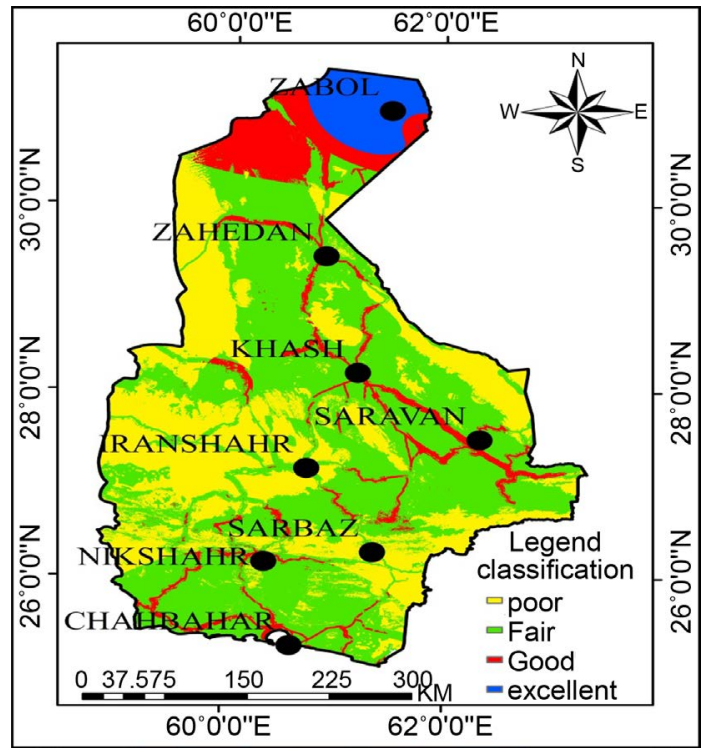

Figure 10. Location of suitable areas for wind farm construction.

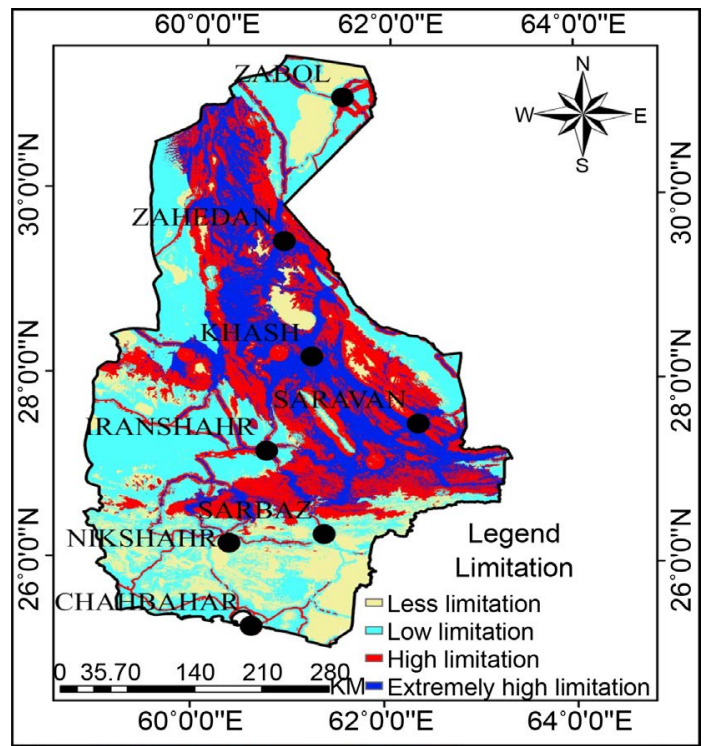

Figure 11. Location of limited areas.

Table 10. Limiting factors, the minimum and maximum distance from the studied criteria [19].

\begin{tabular}{|c|c|c|c|c|}
\hline No. & Factors call & Factor details & Minimum distance & Maximum distance \\
\hline \multirow{3}{*}{1} & & Wildlife refuge & & \\
\hline & Distance from protected area & Protected area & 2000 & 4000 \\
\hline & & Hunting banned area & & \\
\hline 2 & Distance from epicenter & - & 2000 & 10,000 \\
\hline 3 & Distance from fault & - & 1000 & 10,000 \\
\hline 4 & Distance from river & - & 1000 & - \\
\hline 5 & Distance from road & - & 1000 & 10,000 \\
\hline 6 & Distance from town & - & 2000 & 6000 \\
\hline 7 & Distance from villages & - & 1000 & - \\
\hline
\end{tabular}


restrictions and limiting factors, the minimum and maximum distance criteria, respectively.

\subsection{Prioritizing Areas Suitable for Construction of Wind Farms}

To determine the areas prioritized for constructing wind farms, two maps of wind farms locating and wind farms regional restrictions for the construction are consistent with each other. With that in mind such as areas with high potential and the low limits, their area, climatic factors and the field visit, the priorities were determined to build wind farms (Figure 12). Table 12 shows forecasted priorities for the construction of wind farms. According to this table, the areas around the Zabol station are considered first and second priority for constructing wind farms. However, the region experiences 120 days windy condition and the speed and power of the winds will increase the amount of power produced by wind turbines. The third priority to build a wind farm

Table 11. Characteristics of limited areas.

\begin{tabular}{ccccc}
\hline Range & No. & Limitation & Area (ha) & \% of province area \\
\hline \multirow{2}{*}{ Whole zone } & 1 & Less limitation & $3,096,197.11$ & 17.46 \\
& 2 & Low limitation & $5,917,298.94$ & 33.40 \\
Total area & 5 & High limitation & $4,913,183.04$ & 27.56 \\
\hline
\end{tabular}

Table 12. Anticipated priorities for the construction of wind farms.

\begin{tabular}{cccccc}
\hline Station & Longitude & Latitude & Wind speed (knot) & Surface & Priority \\
\hline Zabol & 6114 & 3055 & 11.54 & excellent & Priority 1 \\
Zabol & 611 & 3039 & 11.54 & good & Priority 2 \\
Chabahar & 6122 & 2515 & 6.68 & fair & Priority 3 \\
\hline
\end{tabular}

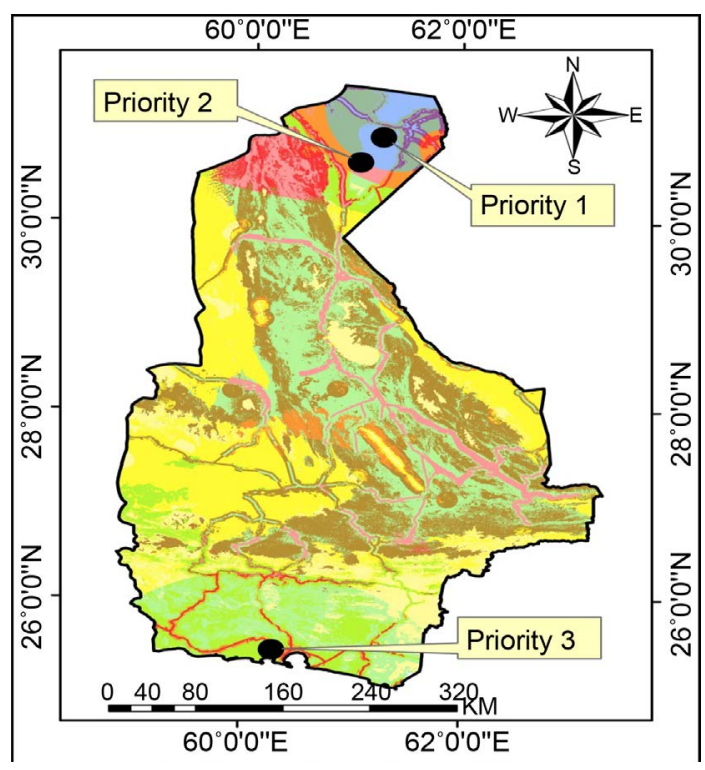

Figure 12. Prioritization of constructing wind farms in the study area. 
was considered Chabahar. Because the area according to Map 12 has low and very low limits, and the wind speed is dominant and is a vast area compared to other stations with a good average. In this section, the essential point is that places like Zahak located in the eastern part of Zabol and has prevailing winds with average speed of 16 knots (the country's Meteorological Agency, the average wind speed data in statistical terms, between 1985 to 2010) and in this case will increase the power of the wind turbines production rate, but in this study because the restrictive criteria (fault, river, village, town, land use...) have also been considered caused this area having many restrictions and too much economically limits not to be considered as a suitable site for wind farm construction and for this it couldn't find a good rank among experts' prioritization.

\section{Conclusion}

Wind turbines should be located at the sites with speedy wind and suitable continuity and lack of environmental barriers. In addition, the dominant wind speed and continuity are also very important factors. However, the vast, flat and almost circular dunes are the most suitable location to install wind turbines. Using AHP and based on specified criteria, the various parts of the region were prioritized regarding the establishment of wind farms. Based on the final map, areas for construction of wind farms in the province were identified. The results indicate a high potential for the construction of wind farms in cities of Zabol and Chabahar. The areas have been determined with regard to a series of factors including wind speed, dominant wind speed, scope, and limits. In this study, among criteria of climatic, geographic, environmental, economic, social and geological, climatic and geographical factors such as wind speed, dominant wind speed, slope and height of the most important location-finding construction of wind farms have been evaluated. In this study, an excellent area for the construction of wind farms in the north area of the study is located in Zabol station with an area of 72.0789842 hectares. Good areas with an area of over 95.186327 hectare in traces include southwest stations of Zabol, Zahedan, Saravan, Khash and Chabahar. However, the fair class with an area of over 79.9285437 hectare includes a wide range of South, Central and East area of the study covering approximately $0.53 \%$ of province area. Findings of this research indicate capability of the GIS in the modeling and helping to plan environmentally as well as combining qualitative and quantitative criteria through various scales. Locating and analyzing with AHP method help planners to take decisions based on better spatial data. It is certainly much more precise criteria to be used more and more to obtain favorable results.

\section{References}

[1] Owusu, P.A. and Asumadu-Sarkodie, S. (2016) A Review of Renewable Energy Sources, Sustainability Issues and Climate Change Mitigation. Civil and Environmental Engineering, 3, 1167990. https://doi.org/10.1080/23311916.2016.1167990

[2] Saghafy, M. (1994) Wind Power and Its Application in Agriculture. Tehran University Press.

[3] Asumadu-Sarkodie, S. and Owusu, P.A. (2016) The Potential and Economic Viability of Wind Farms in Ghana. Energy Sources, Part A: Recovery, Utilization, and Environmental Effects, 38, 695-701. https://doi.org/10.1080/15567036.2015.1122680 
[4] Sharif Moghaddasi, M. (2009) Wind Energy in Iran. Asian Journal on Energy and Environment, 6, 202-205.

[5] Hamouda, Y.A. (2012) Wind Energy in Egypt Economic Feasibility for Cairo. Renewable and Sustainable Energy Reviews, 16, 3312-3319. https://doi.org/10.1016/j.rser.2012.02.058

[6] Masseran, N., Razali, A.M. and Ibrahim, K. (2012) An Analysis of Wind Power Density Derived from Several Wind Speed Density Functions: The Regional Assessment on Wind Power in Malaysia. Renewable and Sustainable Energy Reviews, 16, 6476-6487. https://doi.org/10.1016/j.rser.2012.03.073

[7] Baban, S.M.J. and Parry, T. (2001) Developing and Applying a GIS Assisted Approach to Locating Wind Farms in the UK. Renewable Energy, 24, 59-71. https://doi.org/10.1016/S0960-1481(00)00169-5

[8] Bennui, A., Rattanamanee, P.P., Puetpaiboon, U., Phukpattaranont, P.P. and Chetpattananondh, K.K. (2007) Site Selection for Large Wind Turbine Using GIS. PSU-UNS International Conference on Engineering and Environment, Thailand.

[9] Zendedel, H. (1998) Instructions of Travelling around Iran, Sistan-Baluchestan, Tehran Provinces. Irangardan Publication.

[10] Taylor, B.W. (2004) Introduction to Management Science. Pearson Education Inc., New Jersey.

[11] Bevilacqua, M., D’Amore, A. and Polonara, F. (2004) A Multi-Criteria Decision Approach to Choosing the Optimal Blanching-Freezing System. Journal of Food Engineering, 63, 253-263. https://doi.org/10.1016/j.jfoodeng.2003.07.007

[12] Saaty, T.L. (1980) The Analytic Hierarchy Process: Planning, Priority Setting, Resource Allocation. RWS Publications, Pittsburgh.

[13] Saaty, T.L. (1990) Decision Making for Leaders. RWS publications, Pittsburgh.

[14] Saaty, T.L. (1996) The Analytic Network Process. RWS Publications, Pittsburgh.

[15] Roberts, M. (1975) An Introduction to Town Planning Techniques. Hutchinson, London.

[16] Cheng, C.H. (1996) Evaluating Naval Tactical Missile Systems by Fuzzy AHP Based on the Grade Value of Membership Function. European Journal of Operational Research, 96, 343350. https://doi.org/10.1016/S0377-2217(96)00026-4

[17] Bertolini, M. and Braglia, M. (2006) Application of the AHP Methodology in Making a Proposal for a Public Work Contract. International Journal of Project Management, 24, 422-430. https://doi.org/10.1016/j.ijproman.2006.01.005

[18] Chang, K.F., Chiang, C.M. and Chou, P.C. (2005) Adapting Aspects of GB Tool 200Searching for Suitability in Taiwan. Building and Environment, 42, 310-316. https://doi.org/10.1016/j.buildenv.2005.08.015

[19] Ngai, E.W.T. (2003) Selection of Web Sites for Online Advertising Using the AHP. Information \& Management, 40, 233-242. https://doi.org/10.1016/S0378-7206(02)00004-6

[20] Bowen, W. (1993) AHP: Multiple Criteria Evaluation. In: Klosterman, R., et al., Eds., Spreadsheet Models for Urban and Regional Analysis, Center for Urban Policy Research, New Brunswick.

[21] Taha, H.A. (2003) Operations Research. Pearson Education, Inc., Fayetteville.

[22] Sarkis, J. and Talluri, S. (2004) Evaluating and Selecting E-Commerce Software and Communication Systems for a Supply Chain. European Journal of Operational Research, 159, 318-329. https://doi.org/10.1016/j.ejor.2003.08.018

[23] Kunz, J. (2010) The Analytic Hierarchy Process (AHP). Eagle City Hall Location Options Task Force, 1-25.

[24] Poheker, S.D. and Ramachadran, M. (2004) Application of Multi-Criteria Decision Making to Sustainable Energy Planning-A Review. Renewable and Sustainable Energy Reviews, 8, 
365-381. https://doi.org/10.1016/j.rser.2003.12.007

[25] Bowen, W. (1990) Subjective Judgments and Data Environment Analysis in Site Selection. Computer, Environment and Urban Systems, 14, 133-144.

https://doi.org/10.1016/0198-9715(90)90018-O

[26] Dey, P.K. and Ramachadran, E.K. (2007) Analytic Hierarchy Process Helps Select Site for Limestone Quarry Expansion in Barbados. Journal of Environmental Management, 88, 1384-1395.

[27] Kholil, R.O. (2013) Application of AHP Method for Selecting the Best Strategy to Reduce Environmental Damage Caused by Non-Metallic Mining Case Study in Gunungkidul Regency, Yogyakarta, Indonesia. International Journal of Environmental Engineering Science and Technology Research, 7, 98-109.

[28] Zebardast, E. (2001) Application of AHP in Urban and Regional Planning. Faculty of Fine Arts University of Tehran, Tehran, 10.

[29] Moreno-Jimenez, J.M. (2005) A Spreadsheet Module for Consistent Consensus Building in AHP-Group Decision Making. Group Decision and Negotiation, 14, 89-108.

https://doi.org/10.1007/s10726-005-2407-8

Submit or recommend next manuscript to SCIRP and we will provide best service for you:

Accepting pre-submission inquiries through Email, Facebook, LinkedIn, Twitter, etc. A wide selection of journals (inclusive of 9 subjects, more than 200 journals)

Providing 24-hour high-quality service

User-friendly online submission system

Fair and swift peer-review system

Efficient typesetting and proofreading procedure

Display of the result of downloads and visits, as well as the number of cited articles

Maximum dissemination of your research work

Submit your manuscript at: http://papersubmission.scirp.org/

Or contact cweee@scirp.org 